Working Paper/Document de travail 2013-38

\title{
Some Economics of Private Digital Currency
}

by Joshua S. Gans and Hanna Halaburda 
Bank of Canada Working Paper 2013-38

November 2013

\title{
Some Economics of Private Digital Currency
}

\author{
by \\ Joshua S. Gans ${ }^{1}$ and Hanna Halaburda ${ }^{2}$ \\ 1Rotman School of Management \\ University of Toronto and NBER \\ Corresponding author: joshua.gans@gmail.com \\ ${ }^{2}$ Currency Department \\ Bank of Canada \\ Ottawa, Ontario, Canada K1A 0G9
}

Bank of Canada working papers are theoretical or empirical works-in-progress on subjects in economics and finance. The views expressed in this paper are those of the authors. No responsibility for them should be attributed to the Bank of Canada. 


\section{Acknowledgements}

We thank participants at the NBER Economics of Digitization Conference, Warren Weber and Glen Weyl for helpful comments on an earlier draft of this paper. 


\begin{abstract}
This paper reviews some recent developments in digital currency, focusing on platformsponsored currencies such as Facebook Credits. In a model of platform management, we find that it will not likely be profitable for such currencies to expand to become fully convertible competitors to state-sponsored currencies.
\end{abstract}

JEL classification: D42, E4, L51

Bank classification: Bank notes; Economic models; Payment clearing and settlement systems

\title{
Résumé
}

Les auteurs examinent les récentes évolutions qu'ont connues certaines monnaies numériques, en s'intéressant en particulier aux monnaies exclusives à une plateforme, comme les crédits Facebook. À l'aide d'un modèle formalisant la gestion d'une plateforme, ils concluent qu'il ne sera sans doute pas rentable pour leurs promoteurs que de telles monnaies se développent au point de concurrencer les monnaies émises par les États en devenant pleinement convertibles.

Classification JEL : D42, E4, L51

Classification de la Banque : Billets de banque; Modèles économiques; Systèmes de paiement, de compensation et de règlement 


\section{Introduction}

As digitization has progressed, there has been an increase in private digital currencies. These are virtual goods offered by companies that have the characteristics of money, offering a unit of account, a medium of exchange and a store of value. Examples include Facebook Credits, Microsoft Points or Amazon Coins. They are digital in the sense that they have no physical counterpart; specifically, they are not a claim on real assets. Moreover, they are "issued" by companies whose activities focus on social networking, video games or sales of applications for tablets. In this analysis we ask why companies would find issuing those private digital currencies beneficial, and what strategic considerations are related to such currencies.

It is important to distinguish between private digital currencies and digitization of state-issued currencies. The latter are digitized transactions that involve the execution of a contractual promise to transfer actual currency between two accounts (i.e., from one owner to another owner). This has been extensively studied in the literature on payments systems and, specifically, the contractual terms and standards that govern the settlement of inter-account transfers of currency. ${ }^{1}$ In effect, this is a digital layer to a set of activities that were previously performed non-digitally. In this case, however, digitization plays a straightforward role of reducing transaction costs associated with payments including the carrying of physical money, the storage and protection of that money and the provision of short-term liquidity, as most naturally seen with credit and charge cards. Since this has been extensively studied, we will not concern ourselves with such digitization here.

However, both analyses of digitized money transfer systems and private digital currencies are closely related to economic research on platforms. A platform is a business, mechanism or

\footnotetext{
${ }^{1}$ See Rochet and Tirole (2002) and Gans and King (2003).
} 
institution that brings together two or more distinct parties (or more generally, groups) for their eventual mutual gain. Economic research on platforms has been spurred by payments systems literature, such as the analysis of credit card associations, particularly their pricing and competitive elements. ${ }^{2}$ The platforms literature is related to the issue of private digital currencies in a few ways. First, one can argue that currencies themselves are intrinsically platforms, and that coexisting multiple currencies should be analyzed as platform competition. Second, there have been a number of companies whose primary purpose is the transfer and storage of money; e.g., PayPal, M-Pesa, Bitcoin or Liberty Exchange. Some of them use private digital currencies (Bitcoin, Liberty Exchange), while others do not (PayPal , M-Pesa). But what is interesting is that, for the most part, private digital currencies have been set up in association with non-currency-specific platforms. In this analysis, we will focus exclusively on these.

Consider the example of Linden dollars. These were set up as a currency inside the game Second Life. Participants could earn Linden dollars by trading with other players for virtual goods. Players could bring more Linden dollars to the game by 'buying in' with actual dollars. Moreover, Linden dollars earned in the game could be converted back into actual dollars. Thus, there was the potential for some individuals to earn more actual dollars than they put in. This gave rise to calls for some taxation of those earnings as income but, in reality, the underlying principle was no different from that of casino chips.

Other platform-specific currencies did not have the full convertibility of Linden dollars. Game console makers (Nintendo and Microsoft) required players to pay for points that could be used to purchase games. However, once points were paid for, they could not be converted back. In Microsoft's case, consumers also required points to purchase songs on their Zune portable music player. Nintendo have since phased out their points system and Microsoft has been criticized for

\footnotetext{
${ }^{2}$ See Rochet and Tirole (2003), Armstrong (2006), Weyl (2010).
} 
using points that may obscure the true purchase value for some consumers. By contrast, Sony asked for prepayment of funds to download games to its console, but did not have an alternate unit of account, while Apple allowed consumers to purchase songs and games directly on their iOS platform. It is likely that these systems were set up in response to fees and logistical difficulties related to credit card payments (e.g., for small transactions, those fees could be a burden to merchants). Over time, this became less of an issue as the volume of transactions rose, allowing merchants to bundle smaller consumer transactions into larger ones and save on those payment costs.

While these platform-specific currencies could be seen as moves to improve transactional efficiency subject to existing constraints, others that have evolved appear to be more tightly linked with the overall functioning of the platform. For instance, in the online multiplayer game, World of Warcraft (WoW), players can perform activities and earn WoW Gold that allows them to buy improved weaponary, amongst other things. While this might seem like a currency akin to Monopoly money, WoW Gold can be expanded in supply by the activities of players. For this reason, players are prohibited from trading WoW Gold outside of the game. This, however, has not prevented a black market from arising, literally outsourcing 'Gold farming' to be produced by players in countries with low market wages. In other cases, such as FarmVille, this trading has been alleviated by allowing players to purchase more 'FV Dollars' in the game (and profiting from it). But, unlike Linden dollars, this currency cannot be converted back into real dollars.

In this paper, we focus on these digital currencies that are platform-specific and can be exchanged 'inwards' for real dollars. ${ }^{3}$ In section 2, we will discuss in more detail the case of Facebook Credits that have this feature. We focus on them because commentators in 2011 saw

\footnotetext{
${ }^{3}$ There are currencies that feature the alternative approach: they can be earned via activity only and then converted into real goods and services; for instance, airline and other loyalty points schemes.
} 
them as a threat to traditional currencies. "Could a gigantic nonsovereign like Facebook someday launch a real currency to compete with the dollar, euro, yen and the like?” wrote Matthew Yglesias (2012). And as the payments economist David Evans (2012) stated:

Social game companies could pay developers around the world in Facebook Credits and small businesspeople could accept Facebook Credits because they could use them to buy other things that they need or reward customers with them. In some countries (especially those with national debts that are greater than their GDPs) Facebook Credits could become a safer currency than the national currency.

In other words, there was concern that Facebook Credits could become a currency, like the 2013 attention-getter, Bitcoin, which involved full convertibility.

These predictions have raised issues as to whether such platform-specific currencies should be subject to additional regulation and oversight. However, in our opinion, first it would be useful to understand whether such expansion of the role of platform-specific credits would be in the interests of platform owners. Specifically, would it be worthwhile for a currency such as Facebook Credits to move from limited convertibility to full convertibility? If the answer is no, as we will argue below, then it would appear that the concerns being raised are potentially overblown.

This paper is organized as follows. In the next section, we detail our motivating case of Facebook Credits. While now discontinued, these capture clearly all of the elements of the debates regarding platform-specific currencies. Section 3 then considers a model of platforms and how different attributes of a platform-specific currency can influence platform business models. Our goal here is not to model any one platform in particular, but to give a framework for some suggested forces that will impact on any platform-specific currency choices. Future work, tailored to specific platforms, would likely yield richer results. Section 4 considers some issues associated with regulation. Since these are fast moving and involve deeper issues of monetary economics rather than digitization per se, we merely note some of these. A final section offers some thoughts as to future research directions. 


\section{Motivating Case: Facebook Credits}

In the middle of 2009 the most popular social networking site, Facebook, introduced its virtual currency-Facebook Credits (FB Credits). In 2011, Facebook announced that game developers on its platform would be required to process payments solely through Facebook Credits. ${ }^{4}$ However, the next year, Facebook decided to phase out Credits, since they were a confusing proposition to consumers who also had to purchase points or other currency-like instruments within Facebook games. Nonetheless, the case is instructive because it represents a clear instance of platform-sponsored currencies that, upon their introduction, led many to believe that these could become a significant payment instrument.

To recount this, even before the 2011 announcement, as noted above, many commentators expressed concern that FB Credits could become global currency, and perhaps take over state-issued currency. As early as 2009, predictions were made that "Facebook could rival PayPal by creating a virtual currency and making it usable for financial transactions, essentially making Facebook Credits the currency of the web." ${ }^{5}$ And with 1 billion users, ${ }^{6}$ this currency would be more popular than most state currencies. After the 2011 announcement, those voices became more frequent. ${ }^{7}$ It may have been one of the factors leading the European Central Bank to investigate virtual currencies in $2012 .^{8}$

Facebook equipped its Credits with limited functionality. One can buy Credits (i.e.,

\footnotetext{
4 "Facebook Sets July, 1, 2011 Deadline to Make Credits Sole Canvas Game Payment Option,” Inside Facebook. Retrieved December 4, 2012

(http://www.insidefacebook.com/2011/01/24/facebook-sets-july-1-2011-deadline-to-make-credits-sole-canvas-game -payment-option/).

${ }^{5}$ http://mashable.com/2009/12/15/facebook-credits-currency/

${ }_{7}^{6}$ http://newsroom.fb.com/News/457/One-Billion-People-on-Facebook

7 See, e.g., http://emergentbydesign.com/2011/04/04/the-bank-of-facebook-currency-identity-reputation/ and http://www.slate.com/articles/business/cashless_society/2012/02/facebook_credits_how_ the_social_network_s_currency_could_compete_with_dollars_and_euros_.html.

8 See "Virtual Currency Schemes" European Central Bank, October 2012, available at http://www.ecb.europa.eu/pub/pdf/other/virtualcurrencyschemes201210en.pdf.
} 
exchange state-issued currency for FB Credits) at the rate 50 FB Credits for US\$5, with quantity discounts. ${ }^{9}$ FB Credits can be spent in any Facebook application that accepts them. ${ }^{10}$ It is also important to note that buying FB Credits is not the only way of obtaining them. A user can earn the Credits if they test a new game, or take a survey.

However, the users cannot transfer FB Credits between each other. They also cannot exchange FB Credits back for state-issued currency. This severely limits functionality of FB Credits as a means of payment. Clearly, with such limited functionality, FB Credits cannot really become a global currency rivalling state-issued currencies. Internet pundits, however, claimed that it was only a matter of time, and soon Facebook would turn Credits into a functional currency—by allowing inter-user transfers, and exchanging the FB Credits back into the state-issued currency. ${ }^{11}$

In this paper, we claim that it would not be beneficial for Facebook to equip FB Credits with those additional attributes. Facebook's main source of revenue is advertising, which is linked directly to the activity of the users on the platform. Therefore, Facebook's objective is to increase the activity of its users. Limiting functionality and allowing for both "buying" and "earning" are features that maximize activity on the platform. Users spend FB Credits to enhance their platform experience, which increases their utility from using the platform and leads to more activity. With "buying” and "earning," both time-poor and time-rich users obtain the Credits. If Facebook were to allow for reverse exchange (i.e., exchanging FB Credits to state currency), the time-rich users would sell the Credits they earned without increasing their activity on the platform. Allowing a transfer of FB Credits between users opens a way for the exchange of FB Credits into state-issued currency to bypass the platform: users can transfer FB Credits and pay each other outside the

\footnotetext{
${ }^{9}$ For example, for $\$ 10$ there is a 5\% bonus, and one receives 105 Credits.

${ }^{10}$ The applications were required to use FB Credits between July 2011 and June 2012. Before and after that period, use of FB Credits was voluntary.

11 See, e.g., http://www.slate.com/articles/business/cashless_society/2012/02/facebook_credits_how_the_social_ network_s_currency_could_compete_with_dollars_and_euros_.html.
} 
platform for the acquired Credits, as has happened with WoW Gold. Thus, current functionality of FB Credits is optimal for Facebook’s objective.

\section{The Model}

Consider an environment with one platform and two users, $A$ and $B .^{12}$

\subsection{Users}

Each user $i$ can spend some time $x_{i}$ using the platform, which yields utility $v\left(x_{i}, x_{j}\right)$. To account for consumption complementarity between the two users, the utility of $i$ depends on that user's own consumption $\left(x_{i}\right)$ as well as the consumption of the other user $\left(x_{j}\right)$ The utility of an agent increases as the agent spends more time on the platform (but the rate of increase is declining). Due to complementarity, the agent's utility and marginal utility increases also when the other agent spends more time on the platform; i.e., $\frac{\partial v\left(x_{i}, x_{j}\right)}{\partial x_{i}}>0, \frac{\partial^{2} v\left(x_{i}, x_{j}\right)}{\partial x_{i}^{2}}<0, \frac{\partial v\left(x_{i}, x_{j}\right)}{\partial x_{j}}>0$ and $\frac{\partial^{2} v\left(x_{i}, x_{j}\right)}{\partial x_{i} \partial x_{j}}>0$.

Each user has total time $Z$ available. The time can be spent either using the platform or working. When working, the user can earn wage $w$ per unit of time. The total amount of money earned allows the user to consume a numeraire good (i.e., a composite of goods and services consumed outside of the platform), which adds to the user's utility. Both users are the same, with the exception of the wage-user $A$ earns a higher wage than user $B\left(w_{A}>w_{B}\right)$. Hence, if user $i$ spends $n_{i}$ time to earn the numeraire, then he can consume $n_{i} w_{i}$ of the numeraire

Each user aims to maximize their utility given the time constraint:

$$
\max _{x_{i}, n_{i}} v\left(x_{i}, x_{j}\right)+n_{i} w_{i}
$$

\footnotetext{
${ }^{12}$ The model can be easily extended to $A$ and $B$ denoting types of users with an arbitrary number of agents in each type. The qualitative results stay the same, but the notation is more complicated.
} 
such that $x_{i}+n_{i} \leq Z$.

Clearly, the constraint binds in the optimum, so $n_{i}=Z-x_{i}$, and the utility maximization problem simplifies to $\max _{x_{i}} v\left(x_{i}, x_{j}\right)+\left(Z-x_{i}\right) w_{i}$.

In the interior solution, ${ }^{13}$ the optimal usage $\hat{x}_{i}$ is given by

$$
\frac{\partial v\left(\hat{x}_{i}, x_{j}\right)}{\partial x_{i}}=w_{i} .
$$

Since $\frac{\partial^{2} v\left(x_{i}, x_{j}\right)}{\partial x_{i}^{2}}<0, w_{A}>w_{B}$ implies $\hat{x}_{A}<\hat{x}_{B}$. That is, the user earning the higher wage is choosing to spend less time on the platform.

Example. Suppose that $v\left(x_{i}, x_{j}\right)=x_{i}^{\alpha} x_{j}^{1-\alpha}$, for $\alpha>\frac{1}{2}$. Combining the first-order conditions, we get

$$
\frac{w_{A}}{w_{B}}=\left(\frac{\hat{x}_{B}}{\hat{x}_{A}}\right)^{2(1-\alpha)} .
$$

Clearly, $w_{A}>w_{B}$ implies that $\hat{x}_{A}<\hat{x}_{B}$. Moreover, there are multiple equilibria possible. Any combination of $x_{A}$ and $x_{B}$ such that $\frac{w_{A}}{w_{B}}=\left(\frac{\hat{x}_{B}}{\hat{x}_{A}}\right)^{2(1-\alpha)}$ and $x_{B} \leq Z$ constitutes an equilibrium. Multiplicity of equilibria is not surprising, given the consumption complementarity.

\subsection{The platform}

We assume that the platform's revenue directly depends on the usage, $r\left(x_{A}+x_{B}\right)$ where $r$ $>0$ is the revenue from an additional unit of activity, say from advertising. For now, we assume

${ }^{13}$ Corner solutions may happen for very high and very low $w$ 's. When $w_{i}$ is low enough that $\left.\frac{\partial v\left(\hat{x}_{i}, x_{j}\right)}{\partial x_{i}}\right|_{x_{i}=Z}>w_{i}$, then the user spends all their time using the platform, $\hat{x}_{i}=Z$. Notice that, in such a case, increasing $x_{j}$ does not change $\hat{x}_{i}$, but decreasing $x_{j}$ may decrease $\hat{x}_{i}$ below $Z$ if the derivative decreases to $\left.\frac{\partial v\left(\hat{x}_{i}, x_{j}\right)}{\partial x_{i}}\right|_{x_{i}=Z}<w_{i}$. Similarly, when $w_{i}$ is high enough that $\left.\frac{\partial v\left(\hat{x}_{i}, x_{j}\right)}{\partial x_{i}}\right|_{x_{i}=0}<w_{i}$, then the agent spends no time using the platform, $\hat{x}_{i}=0$. Decreasing $x_{j}$ will not change $i$ 's consumption decision. But increasing $x_{j}$ may induce $i$ to set positive $\hat{x}_{i}>0$, when the increase in $x_{j}$ increases the derivative to $\left.\frac{\partial v\left(\hat{x}_{i}, x_{j}\right)}{\partial x_{i}}\right|_{x_{i}=0}>w_{i}$. 
that this is the only source of the platform's revenue. Under this assumption, the platform aims at maximizing the total usage: $x_{A}+x_{B}$. Later in the analysis, we allow other sources of revenue, e.g., the sale of platform-specific currency. In that latter case, the platform's optimal decisions do not necessarily maximize total usage. Notice that, due to consumption complementarity, there may exist multiple equilibria with different total usage.

Example (continued). Given multiplicity of equilibria, the platform's usage depends on the equilibrium played. In our example, the largest usage that may be obtained in an equilibrium is for $\hat{x}_{B}=Z$ and $\hat{x}_{A}=Z\left(\frac{w_{B}}{w_{A}}\right)^{\frac{1}{2(1-\alpha)}}$. The smallest one is arbitrarily close to 0 , when $\hat{x}_{B}=\varepsilon \neq 0$ and $\hat{x}_{A}=\varepsilon\left(\frac{w_{B}}{w_{A}}\right)^{\frac{1}{2(1-\alpha)}}$.

\subsection{Enhancing the platform: "buying" and "earning"}

Suppose that now the platform allows the users to acquire options, $e_{i}$, that enhance the value of platform usage. For example, this may be additional options in a game. The enhancement increases the usage utility; i.e., for the same level of usage, $v\left(x_{i}, e_{i}^{\prime}, x_{j}\right)>v\left(x_{i}, e_{i}, x_{j}\right)$ for $e_{i}^{\prime}>e_{i}$.

Moreover, we assume that $\frac{\partial v\left(x_{i}, e_{i}^{\prime}, x_{j}\right)}{\partial x_{i}}>\frac{\partial v\left(x_{i}, e_{i}, x_{j}\right)}{\partial x_{i}}, \frac{\partial v\left(x_{i}^{\prime}, e_{i}, x_{j}\right)}{\partial e_{i}}>\frac{\partial v\left(x_{i}, e_{i}, x_{j}\right)}{\partial e_{i}}$ for $x_{i}^{\prime}>x_{i}$ and $\frac{\partial v\left(x_{i}, e_{i}, x_{j}\right)}{\partial e_{i}} \rightarrow \infty$ as $e_{i} \rightarrow 0 .^{14}$ The enhancement may be obtained by "buying” it, or by “earning” it (e.g., through testing functionality or simply by playing the game more intensively). Specifically, we assume that $e_{i}=\gamma y_{i}+\phi t_{i}$, where $y_{i}$ are the units of the numeraire ("buying") and $t_{i}$ are in units of time (“earning”).

User $i$ 's utility in the environment with the enhancement is

$$
v\left(x_{i}, e_{i}\left(t_{i}, y_{i}\right), x_{j}\right)+\left(Z-x_{i}-t_{i}\right) w_{i}-y_{i},
$$

14 This is on top of the usual second-order conditions: $\frac{\partial^{2} v\left(x_{i}, e_{i}, x_{j}\right)}{\partial x_{i}^{2}}<0$ and $\frac{\partial^{2} v\left(x_{i}, e_{e}, x_{j}\right)}{\partial e_{i}^{2}}<0$. 
which the user maximizes by choosing $x_{i}, t_{i}$, and $y_{i}$ subject to the constraints that $y_{i} \leq\left(Z-x_{i}-t_{i}\right) w_{i}$ and $Z \geq x_{i}+t_{i}$. For a solution interior in all three variables, the first-order conditions are

$$
\begin{aligned}
& \text { w.r.t. } x_{i}: \frac{\partial v\left(x_{i}, e_{i}, x_{j}\right)}{\partial x_{i}}=w_{i} \\
& \text { w.r.t. } t_{i}: \frac{\partial v\left(x_{i}, e_{i}, x_{j}\right)}{\partial e_{i}} \phi=w_{i} \\
& \text { w.r.t. } y_{i}: \frac{\partial v\left(x_{i}, e_{i}, x_{j}\right)}{\partial e_{i}} \gamma=1 .
\end{aligned}
$$

Notice, however, that $t_{i}$ and $y_{i}$ are perfect substitutes in achieving $e_{i}$. Therefore, each user chooses only one way of obtaining $e_{i}$, whichever is cheapest. "Buying" a unit of $e_{i}$ costs the user $\frac{1}{\gamma}$, while “earning” it costs $\frac{w_{i}}{\phi}$.

If $w_{i}<\frac{\phi}{\gamma}$, then user $i$ only "earns" the enhancement, and $y_{i}=0$. Then, the two relevant first-order conditions are

$$
\frac{\partial v\left(x_{i}, e_{i}, x_{j}\right)}{\partial x_{i}}=w_{i} \text { and } \frac{\partial v\left(x_{i}, e_{i}, x_{j}\right)}{\partial e_{i}} \phi=w_{i} .
$$

When $w_{i}>\frac{\phi}{\gamma}$, then user $i$ only "buys," i.e., $t_{i}=0$. Then, the two relevant first-order conditions are

$$
\frac{\partial v\left(x_{i}, e_{i}, x_{j}\right)}{\partial x_{i}}=w_{i} \text { and } \frac{\partial v\left(x_{i}, e_{i}, x_{j}\right)}{\partial e_{i}} \gamma=1
$$

For exogenously given $w$ 's, $\phi$, and $\gamma$, we assume here that $Z$ is large enough that solutions on the relevant parameters ( $x_{i}$ and $t_{i}$, or $x_{i}$ and $y_{i}$ ) are interior. For an interior $x_{i}$, we can prove the 
following result.

Lemma 1. Holding $e_{i}$ and $x_{j}$ fixed, a user $i$ with lower $w_{i}$ optimally chooses higher usage, $x_{i}$.

PROOF: Since $Z$ is large enough for $x_{i}$ to be interior for both users, $\frac{\partial v\left(x_{i}, e_{i}, x_{j}\right)}{\partial x_{i}}=w_{i}$. With $w_{A}>w_{B}$, for the same $e_{i}$ and $x_{j}$, the derivative is higher for the higher-wage user. And since $\frac{\partial^{2} v\left(x_{i}\right)}{\partial x_{i}^{2}}<0$, the derivative is higher for smaller usage $x_{i}$. Hence $x_{A}<x_{B}$ if $e_{i}$ and $x_{j}$ are unchanged.

Given that users have different wages, in equilibrium it will not be the case that $e_{i}$ and $x_{j}$ are the same for both users. With the higher usage $x_{i}$, the marginal benefit of enhancement is higher.

Thus, users with lower $w_{i}$ choose larger $e_{i}$, which further increases their optimal usage.

Lemma 2. The low-wage user acquires more enhancements and has higher usage in equilibrium.

PROOF: We conduct this proof in two steps. In the first one, we show that the low-wage user acquires more enhancements for a fixed $x_{i}$ and $x_{j}$. In the second step, we combine the result of the first step and of Lemma 1 to complete the proof for the equilibrium outcome.

When both $w_{A}$ and $w_{B}$ are greater-or both lower-than $\frac{\phi}{\gamma}$, we find that the low-wage user acquires more enhancement directly from the second-order conditions (for a fixed $x_{i}$ and $x_{j}$ ). The interesting case is when $w_{A}>\frac{\phi}{\gamma}>w_{B}$. In this case, the first-order conditions are $\frac{\partial v}{\partial e_{B}} \phi=w_{B}$ and $\frac{\partial v}{\partial e_{A}} \gamma=1$. Those conditions imply that $\frac{\partial v}{\partial e_{B}}=\frac{w_{B}}{\phi}$ and $\frac{\partial v}{\partial e_{A}}=\frac{1}{\gamma}$. And since $\frac{\phi}{\gamma}>w_{B} \Leftrightarrow \frac{1}{\gamma}>\frac{w_{B}}{\phi}$, then $\frac{\partial v}{\partial e_{A}}>\frac{\partial v}{\partial e_{B}}$. Therefore, if faced with the same $x_{i}$ and $x_{j}$, $e_{A}<e_{B}$.

In the second step of the proof, notice, from Lemma 1, that we know that $x_{A}<x_{B}$ for the same $e_{i}$ and $x_{j}$. Moreover, because own consumption has a larger effect on utility than $x_{j}$, it is still true that $x_{A}\left(x_{B}\right)<x_{B}\left(x_{A}\right)$ for the same $e_{i}$. Moreover, from the previous step of this proof, given $x_{i}$ and $x_{j}, e_{A}<e_{B}$ reinforces the fact that in equilibrium $x_{A}^{*}<x_{B}^{*}$ (i.e., $\left.x_{B}(e)-x_{A}(e)<x_{B}^{*}\left(e_{B}^{*}\right)-x_{A}^{*}\left(e_{A}^{*}\right)\right)$.

Notice that usage increases more when both ways of procuring $e_{i}$ are available. Because users 
choose the cheapest way, they choose more $e_{i}$ than they would if only one way of procurement was allowed. Higher $e_{i}$ leads to higher $x_{i}$. Moreover, due to consumption complementarities, it further increases the consumption of the other user, $x_{j}$. Therefore, by allowing users to both "earn" and "buy" an enhancement of the platform usage (e.g., Facebook points), the platform increases usage, as compared to allowing for only one type of enhancement procurement.

Proposition 1. When the platform allows for both "earning" and "buying" of the enhancement, the direct usage, $x_{A}+x_{B}$, (weakly) increases by more than when the platform allows for only one type of enhancement procurement (only "buying” or only “earning”).

The increase is "weak," because if both users are choosing the same means of obtaining the enhancement, and the only option is the optimal option, then adding a new option does not strictly improve usage. The following proof focuses on the interesting case where improvement is strict.

PROOF: Let $w_{A}>\frac{\phi}{\gamma}>w_{B}$. Suppose that only option "buy" is available. Both $i=A, B$ choose their enhancement investment and usage based on (7). Let $B$ 's optimal choices in this case be $\hat{x}_{B}$ and $\hat{e}_{B}$.

When it becomes possible to "earn," user $B$ prefers to go for the new option, and chooses enhancement $\hat{\hat{e}}_{B}$ according to condition (6). Since $\frac{w_{B}}{\phi}<\frac{1}{\gamma}$, then $\frac{\partial v\left(\hat{x}_{B}, \hat{e}_{B}, x_{A}\right)}{\partial e_{B}}>\frac{\partial v\left(\hat{x}_{B}, \hat{e}_{B}, x_{A}\right)}{\partial e_{B}}$, which implies $\hat{\hat{e}}_{B}\left(\hat{x}_{B}\right)>\hat{e}_{B}\left(\hat{x}_{B}\right)$. But then also $\hat{\hat{x}}_{B}>\hat{x}_{B}$. So, in equilibrium $\hat{\hat{e}}_{B}$ and $\hat{\hat{x}}_{B}>\hat{x}_{B}$. Given the complementarity in users' activity, increasing $x_{B}$ also increases $x_{A}$. Thus, allowing for "earning” of platform enhancement along with "buying” increases total platform usage, by increasing both $x_{B}$ and $x_{A}$.

In a similar way, we can also show that starting from "earning” only, and then allowing "buying" as well, increases total platform usage by increasing both $x_{A}$ and $x_{B}$.

It is useful to consider the relevance of this proposition for digital currency. For instance, Facebook Credits represent a unit of account. It could have been that, like Microsoft and Nintendo, these credits were solely bought. In this way, they would merely be a way of converting real currency into on-platform payments. However, to the extent that some users of the platform are 
income or wealth constrained, this would reduce their use of enhancements. Complementarity amongst users would then imply a reduction in overall activity on the platform. Instead, by offering a means of earning enhancements, the platform provides an alternative pathway for income-constrained users. Of course, this may be strengthened if such earning was itself platform activity—as sometimes occurs—but we have supressed that effect here. Later, in section 3.5, we also discuss how Proposition 1 may sometimes fail if the platform has different objectives than maximizing total usage.

The proposition also demonstrates that allowing 'inwards convertibility' from real currency onto the platform encourages more usage from income-rich users. Once again, complementarity amongst users leads to more overall usage from convertibility. Thus, while World of Warcraft may officially prohibit 'Gold farming,' there is a sense in which it increases platform usage. Of course, it could be imagined that digital currencies associated with platforms could go further and allow 'outwards convertibility.' It is this feature that would put those currencies on a path to competing with state-issued currencies. We examine this option next.

\subsection{Reverse exchange}

In this section, we show that if the platform were to allow for the reverse exchange of “earned” credits into state-issued currency, it would decrease platform usage.

Proposition 2. If the platform allows for the reverse exchange of $e_{i}$ into $y_{i}$ at any positive rate, it lowers platform usage.

ProOF: Suppose that user $i$ can spend $t_{i}$ to get $e_{i}=\phi t_{i}$, but then can convert it back into cash at a rate of $\mu: y_{i}=\frac{e_{i}}{\mu}=\frac{\phi t_{i}}{\mu}$. Then, the effective wage of user $i$ is $\frac{y_{i}}{t_{i}}=\frac{\phi}{\mu}$. If the platform puts no restrictions on this exchange, it allows all agents with outside wage $w_{i}<\frac{\phi}{\mu}$ to achieve the effective wage of $\hat{w}=\frac{\phi}{\mu}$. But, from the previous results, we know that increasing the wage lowers the equilibrium usage $x_{i}$, and also lowers how much of $e_{i}$ is 
actually used by the agent on the enhancement, as the agent may redeem ${ }^{15}$ part or all of $e_{i}$ for $\left.y_{i}\right)$.

The proof here does not take into account the fact that reverse exchange would be costly for the platform. In other words, it is unambiguously detrimental to the platform. Thus, as long as the goal of the platform is to maximize direct activity $\left(x_{A}+x_{B}\right)$, platforms have no incentive to allow for 'outwards convertibility' or reverse exchange. In other words, despite the concern of commentators, platforms that utilize digital currencies for 'within platform' transactions have no incentive to move toward full convertibility.

It is worth considering the assumption that drives this strong result. Here we have assumed that platform activity-including the incentive to purchase an enhancement-is solely driven by utility earned within the platform. Specifically, the enhancement increases the marginal utility from activity and is reduced if currency is redeemed outside of the platform. However, it could be the case that by earning the enhancement, activity is increased even if the currency earned is redeemed rather than spent within the game. In this case, the incentive to earn that currency increases activity and could be enhanced by allowing convertibility. This may be part of the rationale for allowing full convertibility of Linden dollars in the game Second Life.

\subsection{Optimal choice of $\gamma$ and $\phi$}

Until now, we have taken $\gamma$ and $\phi$ as given. Typically, however, the platform sets $\gamma$ and $\phi$. Each user's choice of whether to earn or purchase an enhancement depends on the prices, $1 / \gamma$ and $1 / \phi$, and their relationship to the user's wage. The prices chosen by a platform depend on its precise objective. Thus far, we have focused on the impact of various platform choices on

\footnotetext{
15 Since part or all of the enhancement is redeemed, it does not enter as $e_{i}$ into $v\left(x_{i}, e_{i}, x_{j}\right)$.
} 
$x_{A}+x_{B}$, direct platform usage. This would be relevant if the platform's only source of revenue was, say, advertising. In this case, the platform would aim to set both $\gamma$ and $\phi$ as high as possible so that, regardless of how a user chooses to obtain the enhancement, each does so. In effect, the enhancement would be built into the platform and there would be little interesting question regarding currencies.

In some important situations, the platform may also earn the same advertising revenue from users' activity while earning an enhancement. In this case, the platform would aim to maximize $r\left(x_{A}+x_{B}+t_{A}+t_{B}\right)$. The platform may then benefit from users engaging in a variety of activities (depending on the nature of $v($.$) ), but, regardless, it would want \phi$ to be as high as possible so that all users would earn the enhancement. For $\gamma$, the platform faces a trade-off. Decreasing $\gamma$ can induce high-wage types to switch their activity toward earning the enhancement, which directly increases $t_{A}$. However, this involves some substitution from $x_{A}$ which, depending upon $v($.), may lead to a reduction in activity by $B$. Thus, it is not possible to characterize this price in the general case.

Of course, the purchases of enhancements can also represent an alternative revenue stream for the platform. In this case, it would be reasonable to consider the platform as maximizing $r\left(x_{A}+x_{B}\right)+\left(y_{A}+y_{B}\right)$ or $r\left(x_{A}+x_{B}+t_{A}+t_{B}\right)+\left(y_{A}+y_{B}\right)$. Depending on the level of $r$, the platform may prefer to withdraw the possibility of earning an enhancement and force all agents to buy it. That is, in such a case, Proposition 1 may fail. Regardless of whether Proposition 1 holds or fails, prices will be set so that each user's time constraint is binding and focused on the platform, either through activity or income. That is, for users buying an enhancement, $t_{i}=0$ and $y_{i}=\left(Z-x_{i}\right) w_{i}$, while for a user earning the enhancement, $y_{i}=0$ and $t_{i}=Z-x_{i}$. 
This allows us to identify the first-order conditions for users. For users earning the enhancement, it is

$$
\left.\frac{\partial v\left(x_{i}, e_{i}, x_{j}\right)}{\partial x_{i}}\right|_{e_{i}=\phi\left(Z-x_{i}\right)}=\left.\phi \frac{\partial v\left(x_{i}, e_{i}, x_{j}\right)}{\partial e_{i}}\right|_{e_{i}=\phi\left(Z-x_{i}\right)}
$$

Notice that this condition is independent of $w_{i}$. Thus, the optimal usage schedule for those earning the enhancement is independent of wage. That is, if both high-wage and low-wage agents decide to earn the enhancement, they would earn the same $e_{i}$ and consume the same $x_{i}$. For a user buying the enhancement, we have

$$
\left.\frac{\partial v\left(x_{i}, e_{i}, x_{j}\right)}{\partial x_{i}}\right|_{e_{i}=\gamma\left(Z-x_{i}\right) w_{i}}=\left.w_{i} \gamma \frac{\partial v\left(x_{i}, e_{i}, x_{j}\right)}{\partial e_{i}}\right|_{e_{i}=\gamma\left(Z-x_{i}\right) w_{i}}
$$

Thus, users who buy the enhancement will differ in their usage levels, depending on the wage. This suggests that allowing users to buy enhancements can be useful when it is optimal to exploit their differential usage rather than ignore it. Of course, a precise characterization is not possible in the general case. For our running example, however, we can provide a more precise conclusion. Example (continued). Suppose that, in our example, the platform introduces the enhancement and now $v\left(x_{i}, e_{i}, x_{j}\right)=x_{i}^{\alpha} x_{j}^{1-\alpha} e_{i}^{\beta}$. Moreover, $e_{i}=\gamma y_{i}+\phi t_{i}$. Then, user $i$ 's utility is $x_{i}^{\alpha} x_{j}^{1-\alpha}\left(\gamma y_{i}+\phi t_{i}\right)^{\beta}+\left(Z-x_{i}-t_{i}\right) w_{i}-y_{i}$. For $w_{i}<\frac{\phi}{\gamma}$, i.e., $y_{i}=0$ :

$$
\left(\begin{array}{l}
\alpha x_{i}^{\alpha-1} x_{j}^{1-\alpha}\left(\phi t_{i}\right)^{\beta}=w_{i} \\
\phi \beta x_{i}^{\alpha} x_{j}^{1-\alpha}\left(\phi t_{i}\right)^{\beta-1}=w_{i}
\end{array} \Rightarrow t_{i}=\frac{\beta}{\alpha} x_{i} .\right.
$$

Using $t_{i}=\frac{\beta}{\alpha} x_{i}$, the first-order condition yields $x_{i}^{\alpha+\beta-1}=\frac{w_{i}}{\phi^{\beta} \alpha^{1-\beta} \beta^{\beta} x_{j}^{1-\alpha}}$ if the solution is interior, i.e., when $t_{i}<Z-x_{i}$. When $\phi$ is large enough (i.e., $\phi>\frac{\alpha}{\beta}\left(\frac{w_{i}(\alpha+\beta)^{\alpha+\beta-1}}{x_{j}^{1-\alpha}(\alpha Z)^{\alpha+\beta-1} \alpha}\right)^{\frac{1}{\beta}}$ ), so that $t_{i}=Z-x_{i}$, the user's problem becomes $\max _{x_{i}} x_{i}^{\alpha} x_{j}^{1-\alpha}\left(\phi\left(Z-x_{i}\right)\right)^{\beta}$. The optimal usage is then $x_{i}=\frac{\alpha Z}{\alpha+\beta}$ and $t_{i}=\frac{\beta Z}{\alpha+\beta}$. Notice that it does not depend on $\phi$ once the time constraint is binding.

$$
\text { For } w_{i}>\frac{\phi}{\gamma} \text {, i.e., } t_{i}=0
$$




$$
\left(\begin{array}{l}
\alpha x_{i}^{\alpha-1} x_{j}^{1-\alpha}\left(\gamma y_{i}\right)^{\beta}=w_{i} \\
\gamma \beta x_{i}^{\alpha} x_{j}^{1-\alpha}\left(\gamma y_{i}\right)^{\beta-1}=1
\end{array} \Rightarrow y_{i}=\frac{\beta}{\alpha} x_{i} w_{i}\right.
$$

And further it yields $x_{i}^{\alpha+\beta-1}=\frac{w_{i}^{1-\beta}}{\gamma^{\beta} \alpha^{1-\beta} \beta^{\beta} x_{j}^{1-\alpha}}$ for the interior solution. The corner solution, which arises when $\gamma$ is sufficiently large, is: $x_{i}=\frac{\alpha Z}{\alpha+\beta}$ and $y_{i}=\frac{\beta Z}{\alpha+\beta} w_{i}$.

Depending on the wages and "prices" ( $\gamma$ and $\phi)$, there are three situations possible: both agents earn the enhancement, both buy it, or one buys and the other earns. We analyze each case in turn (for the interior solution).

1. When both agents are earning the enhancement, then any consumption patterns in equilibrium must satisfy $\left(\frac{x_{B}}{x_{A}}\right)^{2(1-\alpha)-\beta}=\frac{w_{A}}{w_{B}}$. Together with the formula for $x_{i}$ derived above, it yields

$$
x_{i}^{\beta}=\left(\frac{w_{j}}{w_{i}}\right)^{\frac{1-\alpha}{2(1-\alpha)-\beta}} \frac{w_{i}}{\alpha^{1-\beta} \beta^{\beta} \phi^{\beta}} .
$$

This is a complicated formula, but it uniquely gives $x_{i}$ with respect to the exogenous parameters.

2. When both agents are buying the enhancement, then in any equilibrium it must be that $\left(\frac{x_{B}}{x_{A}}\right)^{2(1-\alpha)-\beta}=\left(\frac{w_{A}}{w_{B}}\right)^{1-\beta}$. Then,

$$
x_{i}^{\beta}=\left(\frac{w_{j}}{w_{i}}\right)^{\frac{(1-\beta)(1-\alpha)}{2(1-\alpha)-\beta}} \frac{w_{i}^{1-\beta}}{\alpha^{1-\beta} \beta^{\beta} \phi^{\beta}} .
$$

3. When agent $A$ is buying the enhancement, while agent $B$ is earning, then in any equilibrium it must be that $\left(\frac{x_{A}}{x_{B}}\right)^{2(1-\alpha)-\beta}=\frac{w_{B}}{w_{A}^{1-\beta}}\left(\frac{\gamma}{\phi}\right)^{\beta}$. And then,

$$
\begin{aligned}
& x_{A}^{\beta}=\left(\frac{w_{B}}{w_{A}^{1-\beta}}\right)^{\frac{1-\alpha}{2(1-\alpha)-\beta}}\left(\frac{\gamma}{\phi}\right)^{\frac{\beta(1-\alpha)}{2(1-\alpha)-\beta}} \frac{w_{A}^{1-\beta}}{\gamma^{\beta} \alpha^{1-\beta} \beta^{\beta}} \\
& x_{B}^{\beta}=\left(\frac{w_{A}^{1-\beta}}{w_{B}}\right)^{\frac{1-\alpha}{2(1-\alpha)-\beta}}\left(\frac{\phi}{\gamma}\right)^{\frac{\beta(1-\alpha)}{2(1-\alpha)-\beta}} \frac{w_{B}}{\phi^{\beta} \alpha^{1-\beta} \beta^{\beta}}
\end{aligned}
$$

Notice that, in all three cases, introducing the enhancement eliminates multiplicity of equilibria, since now $x_{i}$ are uniquely characterized by the exogenous parameters.

Now consider the platform setting prices $\phi$ and $\gamma$ to maximize its objective. We consider four possible objective functions for the platform:

(1) $\max r\left(x_{A}+x_{B}\right)$ : The platform is indifferent on whether to buy or earn. Whether $\gamma$ is so high 
that both buy, $\phi$ so high that both earn, or one buys and one earns, the platform can always achieve the global maximum of $x_{A}=x_{B}=\frac{\alpha Z}{\alpha+\beta}$.

(2) $\max r\left(x_{A}+x_{B}\right)+\left(y_{A}+y_{B}\right)$ : The platform raises $\gamma$ so that not only both users buy the enhancement, but both reach the corner consumption schedule. The platform reaches the global maximum of $x_{A}=x_{B}=\frac{\alpha Z}{\alpha+\beta}$ and $y_{i}=\frac{\beta Z}{\alpha+\beta} w_{i}, i=A, B$.

(3) $\max r\left(x_{A}+x_{B}+t_{A}+t_{B}\right)$ : The platform raises $\phi$ so that not only do both users earn the enhancement, but both reach the corner consumption schedule. The platform reaches the global maximum of $x_{A}=x_{B}=\frac{\alpha Z}{\alpha+\beta}$ and $t_{A}=t_{B}=\frac{\beta Z}{\alpha+\beta}$ earning 2Z. If the platform were to set $\phi$ lower so that $w_{B}<\frac{\phi}{\gamma}<w_{A}$, then $t_{A}=0$ and $x_{A}=\frac{\alpha Z}{\alpha+\beta}$. Thus, the platform would earn $Z\left(1+\frac{\alpha}{\alpha+\beta}\right)<2 Z$.

(4) max $r\left(x_{A}+x_{B}+t_{A}+t_{B}\right)+\left(y_{A}+y_{B}\right)$ : Optimal prices (and optimal users' consumption schedule) depend on $w_{i}$ 's and $r$. The interesting case is when $w_{B}<r<w_{A}$. Then the platform is strictly better off by setting the prices such that user A buys and user B earns the enhancement with consumption achieving a global maximum, $x_{A}=x_{B}=\frac{\alpha Z}{\alpha+\beta}, t_{B}=\frac{\beta Z}{\alpha+\beta}$ and $y_{A}=\frac{\beta Z}{\alpha+\beta} w_{A}$.

\subsection{Summary}

For a platform whose main source of revenue is advertising (e.g., Facebook), its objective is to increase the activity of its users (e.g., the use of social games). When activity on the platform is more valuable for a user when other users increase their activity (e.g., from the social component), there is complementarity in activity on the platform. A platform can provide an enhancement of user experience to encourage more activity (e.g., buying special versions of crops for your farm in FarmVille, which have a higher yield than regular corps). Higher activity by one user increases the utility - and activity_of other users, due to the complementarity. For this reason, if two users acquire the enhancement, the increase in activity is larger than double the increase of activity resulting from a single user's enhancement. Therefore, it is optimal for the platform to encourage all users to acquire the enhancement. But some users may find the monetary cost too high, e.g., if they have a low wage. Then, the platform gains if it allows for both "buying" and "earning" the enhancement. High-wage users will prefer to spend money rather than time, 
while low-wage users can spend time instead of money. Both types will acquire the enhancement and increase activity on the platform.

This reflects the policies of many social networks and also some gaming platforms. Of particular significance is Proposition 2, which prevents platform-specific currencies from being traded back for state-issued currency. This provides a strong result that such platforms are not interested in introducing currencies that would directly compete with existing state-issued currencies. That said, for a platform such as Facebook, there is a flow of money back through developer payments: that is, a developer writes a game that induces people to purchase enhancements. The developer then receives part of the revenue that Facebook receives when Credits are purchased. Nonetheless, this is really just an extension of the platform notion, where the game itself is the platform of interest. Indeed, in mid-2012, Facebook announced that it would phase out Credits by the end of 2013, and rely only on state-issued currencies. The users often needed to further convert Facebook Credits into currencies within apps and games, e.g., zCoins in Zynga’s games. Users and developers were against this additional layer of complication and wanted a direct link to state-issued currencies. This is consistent with the model, in that, for Facebook’s core activity, literally the activity or news feed, all features were available to all users. It could still earn essentially 'referral' fees for revenue generated by others on its platform, but for its core activity, a currency would perform no additional role.

By contrast, it is easy to imagine that app developers such as Zynga introduced their own currencies for exactly the same reason as in our main model: to increase activity on their "app platform.” Just as Facebook Credits once bought or earned cannot be exchanged back into cash, so zCoins—once bought or earned—cannot be exchanged back into state-issued currency (or indeed Facebook Credits when they were available). This policy is driven by Zynga's objective to 
maximize activity on its own platform. This may, however, conflict with Facebook's objective to increase activity on the Facebook platform, possibly across different apps. A richer model would be required to explore issues arising from interlocking platforms.

A distinct argument lies behind Amazon Coins introduced in the beginning of 2013. Amazon announced that it would give away "millions of U.S. dollars worth" of Amazon Coins to customers, starting in May 2013. Like all other introductions of digital currencies, this attracted the usual concern about the threat to state-issued currencies. "But in the long term what [central banks] should perhaps be most worried about is losing their monopoly on issuing money,” wrote the Wall Street Journal. "A new breed of virtual currencies are starting to emerge-and some of the giants of the web industry such as Amazon.com Inc. are edging into the market.”16

However, Amazon Coins is simply a subsidy to buyers to participate in the platform, with the purpose of starting and accelerating any indirect network effects on Amazon's app platform. When Kindle Fire users purchase Amazon Coins, they receive an effective discount on apps (from 5 to $10 \%$, depending on how many Coins are purchased), something that was a feature of Facebook Credits as well. Due to uncertainty about the quality of apps, a subsidy to users is more effective than a subsidy to the developers, since users will "vote" with their Coins for the best apps. At the same time, introducing Amazon Coins is potentially more convenient than subsidizing via cash, since it ensures that the subsidy is spent on the Amazon app platform, and not on other services on Amazon or outside.

\section{$4 \quad$ Regulatory Issues}

Our analysis of platform-specific currencies shows that voices calling for specific

${ }^{16}$ Wall Street Journal, Market Watch
http://articles.marketwatch.com/2013-02-13/commentary/37064080 1 currency-war-bitcoin-central-banks 
regulation of them overstate their case, since the purpose of those currencies is a natural complement to the business models associated with platforms such as Facebook or Amazon. To maximally benefit the platform, the use of currencies needs to be restricted. Thus, it is not in the interest of the platforms to provide fully functional currencies that could compete with state currencies.

In our analysis, however, we have not considered Bitcoin, which is a fully convertible, pure digital currency not associated with a given platform. It is explicitly designed to compete with state currencies. In March 2013, the U.S. government for the first time imposed regulations on online currencies. ${ }^{17}$ Virtual currencies are to be regulated by the U.S. Treasury, since the Financial Crimes Enforcement Network (FinCEN) decided they fall under the anti-money-laundering laws. ${ }^{18}$ According to the new rules, transactions worth more than $\$ 10,000$ need to be reported by companies involved in issuing or exchanging online currencies. The rules do not single out Bitcoin, but apply to all "online currencies.” This clarification of FinCEN laws was issued after evidence emerged that Bitcoin is used for illegal activity (e.g., Silk Road). Illegal activity is a concern because the anonymity of Bitcoin allows for untraceable trades.

There may be other reasons to regulate online currencies that apply to both anonymous and account-based currencies. The European Central Bank released a report at the end of 2012 analyzing whether virtual currency schemes can affect price stability, financial stability or payment stability. ${ }^{19}$ The report distinguishes between closed virtual currency schemes (i.e., used only within games or apps, akin to virtual Monopoly money) and virtual currency schemes that interact with state currencies (i.e., can be used to purchase real goods and services, or even directly

\footnotetext{
${ }^{17}$ http://finance.fortune.cnn.com/tag/facebook-credits/

$18 \mathrm{http} / / /$ www.newscientist.com/article/mg21729103.300-us-to-regulate-bitcoin-currency-at-its-alltime-high.html

19 http://www.ecb.europa.eu/pub/pdf/other/virtualcurrencyschemes201210en.pdf The report focused specifically on case studies of Bitcoin and Linden dollars, but the conclusions were more general.
} 
converted to state currencies). ${ }^{20}$ Closed virtual currency schemes are not a concern in the view of the report, since only virtual currency that interacts with the real economy can affect price stability, financial stability and payment stability. However, the report also concluded that, currently, virtual currency that interacts with state currencies poses no risks, since such money creation is at a low level. Moreover, the interaction of Linden dollars, Bitcoin and similar schemes with the real economy is low because those currencies are used infrequently, by a small group of users, and — most importantly — their use is dispersed geographically, across many state currencies, hence the impact on any one state currency is negligible.

In the case of Q-coin, used only in China, the impact could be significant enough for the central bank to step in and regulate the use of virtual currencies. A social networking site, Tencent QQ, introduced Q-coin to allow for virtual payments. This was not a platform-sponsored currency as we have modelled above, but instead a substitute for state-sponsored currency. Indeed, Q-coins are purchased with Chinese state currency. Thus, while Q-coin was intended for the purchase of virtual goods and services provided by Tencent, users quickly started transferring Q-coin as peer-to-peer payments, and merchants started accepting Q-coin as well. ${ }^{21}$ As the amount of Q-coins traded in one year reached several billion yuan, the Chinese authorities stepped in with regulation. In June 2009, the Chinese government banned exchanging virtual currencies for real goods and services, in order to "limit the possible impact on the real financial system.,"22

\section{$5 \quad$ Future Directions}

This paper has considered the economics of pure digital currencies and demonstrated that,

\footnotetext{
${ }^{20}$ The European Central Bank report also acknowledges that virtual currency schemes "can have positive aspects in terms of financial innovation and the provision of additional payment alternatives for consumers” (p. 47). However, the position of a central bank is to protect state currencies from the risks the virtual currencies may pose.

${ }^{21} \mathrm{http} / / /$ voices.yahoo.com/a-virtual-currency-qq-coin-has-taken-real-value-278944.html

22 http://english.mofcom.gov.cn/aarticle/newsrelease/commonnews/200906/20090606364208.html
} 
in most cases, private currencies issued in support of a platform are unlikely to have implications that extend beyond the platform. Of course, our approach has been theoretical, but it does provide a framework to examine digital currencies as a lens for understanding platform strategy.

What is of broader future concern is the emergence of digital currencies that compete with state-issued currency. For this, the gap in economic knowledge arises from an imperfect set of frameworks for analyzing money and its uses per se, let alone whether they are real or virtual. That said, considering our exploration of these issues, we speculate here that platform economics may actually have a role in assisting a broader understanding of monetary economics.

Any currency can be viewed as a platform, where people need to "join" by believing in its value, i.e., they join by accepting it. Transactions occur only between people who accept the currency, i.e., who have joined the platform. Currencies also exhibit network effects: the more people accept it, the more value there is to accepting it.

If we were to consider any other technology platform instead of currency, regulation aiming to limit the impact of virtual currency schemes on existing payment systems (e.g., due to challenges such schemes might pose for the conduct of monetary policy ${ }^{23}$ ) would be akin to protecting the incumbent standard against innovative entrants. We know from the technology literature that such protection usually leads to loss of efficiency, because new entrants can come up with ways to better and more cheaply serve the market, and perhaps also to expand the market.

Is there a good reason for such protection? The 19th and early 20th century in the United States saw a period of so-called "free banking," where private banks were allowed, under some initial conditions, to issue their own currency. That is, the state did not have a monopoly on issuing currency. However, throughout this period, regulatory interventions increased, and in the early 20th century it became common practice to delegalize issuing currency by anyone except the state

${ }^{23}$ E.g., see the European Central Bank Report, p. 37. 
(Frankel, 1998).

The experience of the free banking period showed that currencies may differ from other technology platforms. Especially, there may be a greater value in the monopoly of the state on issuing currency, as it provides greater stability of the financial system. Issuing currency is a source of profit, since the issuer gains seigniorage. As a monopoly, the state would capture the whole seigniorage profit. However, economic historians ${ }^{24}$ argue that other factors lead the government to introduce increasingly stricter regulation and eventually monopolize the issuing of currency. One such factor is frequent bank failures. In a competitive environment, firms often fail and new ones enter. Prior to the early 20th century in the United States, however, bank failures left customers with bank notes redeemable for only a fraction of their nominal value, and sometimes not redeemable at all (i.e., worthless).

This undermined financial stability, and the public’s trust in paper currency overall. Lack of trust sometimes resulted in bank runs, which led to more bank failures. The trust issues were also reflected in exchange rates between currencies from different issuers. Some private bank notes circulated at a discount (i.e., a \$1 bank note was considered worth less than the nominal \$1) when there were doubts about the bank's solvency. Another reason for lower trust was counterfeiting, which is, of course, also a concern with state-issued currency. But with multiple issuers the number and variety of notes in circulation is larger, and it is harder for the public to keep track of genuine features.

Since the notes were only redeemable at the issuing bank and banks were typically local, the acceptance of some notes would be geographically restricted. Further from the issuing bank's location, the notes would be accepted at a discount if they were accepted at all. Both of these factors—lack of trust and varying exchange rates—created difficulties for trade. At times, it even

\footnotetext{
${ }^{24}$ See, e.g., Rockoff (1974) or Smith (1990).
} 
created worries that the trade could collapse altogether.

But how do those well-known factors compare to the analyses in the technology literature? We know that the presence of network effects often creates multiple equilibria—either lots of people join the platform because they expect lots of other people to join, or no one joins because they do not expect others to join. Similar equilibria can be seen in currency usage. Trust in the currency helps to coordinate on the better equilibrium where people generally adopt paper currency. Another parallel in the technology literature is compatibility. Having multiple networks, with limited or no compatibility, lowers efficiency as compared to one single network, since under limited compatibility the network effects cannot be realized to their full value.

This brings out a well-known tension: On the one hand, the presence of multiple competing platforms creates inefficiency by limiting the extent of network effects (when compatibility is limited), and presents the risk of coordination failure, when users will not join at all. On the other hand, a single well-established dominant platform overcomes the issue of coordination and renders compatibility irrelevant, while stifling innovation and possibly extracting monopoly profit from the users. In issuing currency, since the 20th century, states have traditionally considered one single network as the better side of this trade-off. Whether it is still a valid conclusion with respect to online currencies is a question for future research. 


\section{References}

Armstrong, M. (2006), “Competition in two-sided markets,” RAND Journal of Economics, 37 (3), 668-691.

Evans, D.S. (2012), “Facebook Credits: Do Payments Firms Need to Worry,” PYMNTS.com, 28 February, http://www.pymnts.com/briefing-room/commerce-3-0/facebook-commerce-2/FacebookCredits-Do-Payments-Firms-Need-to-Worry-2/

European Central Bank (2012), “Virtual Currency Schemes” European Central Bank, October 2012, available at http://www.ecb.europa.eu/pub/pdf/other/virtualcurrencyschemes201210en.pdf

Frankel, A.S. (1998), "Monopoly and Competition in The Supply and Exchange of Money," Antitrust Law Journal, 66 (2), 313-361.

Gans, J.S. and S.P. King (2003), “The Neutrality of Interchange Fees in Payments Systems,” The B.E. Journal of Economic Analysis and Policy, 3(1).

Rochet, J-C. and J. Tirole (2002), "Cooperation Among Competitors: Some Economics of Payment Card Associations,” RAND Journal of Economics, 33 (4), 549-570.

Rochet, J-C. and J. Tirole (2003), "Platform competition in two-sided markets," Journal of the European Economic Association, 1(4), 990-1029.

Rockoff, H. (1974), “The Free Banking Era: A Reexamination,’ Journal of Money, Credit and Banking, 6(2): 141-167.

Smith, V.C. (1990), “The rationale of central banking and the free banking alternative," LibertyPress.

Weyl, E.G. (2010), “A price theory of multi-sided platforms,” American Economic Review, 100(4), 1642-1672.

Yglesias, M. (2012), “Social Cash: Could Facebook Credits ever compete with dollars and euros?” Slate, 29 February, http://www.slate.com/articles/business/cashless_society/2012/02/facebook_credits_how_t he_social_network_s_currency_could_compete_with_dollars_and_euros_html. 